Journal of Family Studies, vol. 1, 2021, pp. 1-14.

\title{
Parenting, autonomy and academic achievement in the adolescence.
}

\author{
Aguirre-Dávila, E., Morales-Castillo, M. y \\ Moreno-Vásquez, M.
}

Cita:

Aguirre-Dávila, E., Morales-Castillo, M. y Moreno-Vásquez, M (2021). Parenting, autonomy and academic achievement in the adolescence. Journal of Family Studies, 1, 1-14.

Dirección estable: https://www.aacademica.org/eduardo.aguirre/20 ARK: https://n2t.net/ark:/13683/pkHo/cvr

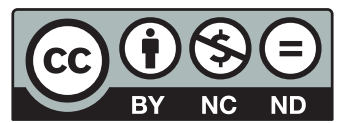




\section{Journal of Family Studies}

\section{Parenting, autonomy and academic achievement in the adolescence}

\section{Eduardo Aguirre-Dávila, Miguel Morales-Castillo \& Manuel Moreno-Vásquez}

To cite this article: Eduardo Aguirre-Dávila, Miguel Morales-Castillo \& Manuel Moreno-Vásquez (2021): Parenting, autonomy and academic achievement in the adolescence, Journal of Family Studies, DOI: 10.1080/13229400.2021.1871935

To link to this article: https://doi.org/10.1080/13229400.2021.1871935

\section{Published online: 13 Jan 2021.}

Submit your article to this journal

山ll Article views: 158

Q View related articles ๘

View Crossmark data 


\title{
Parenting, autonomy and academic achievement in the adolescence
}

\author{
Eduardo Aguirre-Dávila (D), Miguel Morales-Castillo (D) and \\ Manuel Moreno-Vásquez (D)
}

Research Group on Socialization and Parenting, Department of Psychology, Human Sciences Faculty, Universidad Nacional de Colombia, Bogotá, Colombia

\begin{abstract}
Development as a configuration of personal and social conditions makes important to consider both sources of contribution to understand specific trends in adolescence. This study examined the role of adolescent autonomy in the relation between parenting and academic achievement. Two hundred and twentynine mothers and their adolescents (mean age $=11.8 ; \mathrm{SD}=0.93$ ) were surveyed in a cross-sectional design with schools in Colombia, South America. Parenting practices evaluated include parental involvement, expression of affection, communication, and rule-setting; multidimensional autonomy covered cognitive, motivational, and social dimensions in the academic context; academic achievement included grades in Social Sciences, Mathematics, Language, and Natural Sciences. Data were analyzed by estimating structural equation models. Major findings indicate that parenting had indirect effects on academic achievement with the intervention of adolescent autonomy. Communication and parental expression of affection show the greater contribution of parenting to the explanatory model. Cognitive, motivational, and social dimensions of autonomy, in that order, contribute to explain academic achievement, where Social Sciences and Mathematics are the academic areas with major loads. Conclusions include an analysis of parenting practices studied and their relationship with adolescent behaviours and outcomes. Implications address the opportunities offered for the intervention and future studies.
\end{abstract}

\section{ARTICLE HISTORY}

Received 15 May 2020

Accepted 1 January 2021

\section{KEYWORDS}

Parenting; adolescence; autonomy; academic achievement

\section{Introduction}

Parenting is defined as the orientation of efforts and resources of parents to influence the well-being, development, and behaviour of their children (Aguirre-Dávila, 2015; Power et al., 2013; Smetana, 2017), which implies that parent's actions can affect the learning of skills, behaviour patterns, values, and motivations necessary for social and culturally competent functioning of adolescents (Campione-Barr \& Smetana, 2018). Although adolescence is a period of particularities for the relationship between parents and children (Smetana et al., 2015), parenting remains relevant in the adolescent conquest of autonomous functioning and its consequences (Suizzo, 2020). 
A parenting practice that has received attention is the parental rule-setting, which encompasses the manifestation of limits and parameters that can influence adolescent behaviour (Rodríguez-Fernández et al., 2019) acting as a protective factor in risk situations (de Looze et al., 2012) and promoting general positive trends in adolescence (Grolnick et al., 2015). Similarly, parent' manifestation of emotions and teaching children to give and receive affection could buffer against social pressure (Marion et al., 2014) and influence positively adolescent adjustment (Miranda et al., 2016). In the same way, communication between parents and children may affect adolescent behaviour, as a set of interactions in which parents express beliefs and values while sharing emotional elements (Hollmann et al., 2016), which could be a beneficial practice, so that increases in parentchild communication are related to increases in the positive performance of adolescents (Trung \& Ducreux, 2013). Additionally, parental involvement as an active implication of parents in adolescent experiences (Morales-Castillo \& Aguirre-Davila, 2018) has been identified as an important source of influence in adolescent functioning (Wang et al., 2014).

In this frame, while parents are oriented to participate in the development of their children, the latter grow in terms of self-affirmation as individuals (Campione-Barr, 2020). Previous works have examined theory-based psychosocial factors to understand adolescent development. Self-determination theory has been used to provide a framework for autonomy in adolescence, integrating motivation and behavior (Ryan, 2016). From this point of view, parent-adolescent relationships offer a supportive context for the manifestation of autonomy, expressing rationale for activities, acknowledging feelings about activities, avoiding controlling behaviors whenever possible, and allowing the adolescent to choose whether to engage in activities (Ryan et al., 2015; Soenens et al., 2017). In this sense, autonomy corresponds to the personal capacity to be an agent with initiative which compromises different kind of expressions (Deci \& Ryan, 2017), and a multidimensional approach to autonomy includes cognitive, motivational, and social components. Cognitive autonomy implies deployment of planning, organization, and evaluation strategies that guide decision-making (Gestsdottir et al., 2010), while motivational autonomy refers to the desire of carry out an action, either for an intrinsic interest or for the integration of external values in the intrapersonal order (Ryan, 2016), and social autonomy implies that the adolescent takes the initiative in social contexts as an expression of the individual sense of identity (Kirshner, 2018).

Although autonomy could be taken as a tendency towards independence, it can actually be a positioning process with respect to social demands, which insinuates a related autonomy (Grolnick et al., 2017). For parents, to guide their adolescents and promote a healthy development in terms of autonomy is specially challenging, but active expressions of parenting could affect adolescent's experience of act willingly based on true interests or internalized values (Soenens et al., 2017). Specifically, parental behaviours that are related with adolescent autonomy include setting rules (Ren et al., 2017), expression of affection (Kocayörük et al., 2015), communication (Wuyts et al., 2018), and involvement (Wang \& Cai, 2017).

In addition, one area of sensible interest in adolescence is academic performance, where decreases, failure, and dropout are relevant concerns (Hanewald, 2013; Song et al., 2015). In this context, parenting has been related to adolescent performance in specific areas such as math and science (Degol et al., 2017; Morgan et al., 2016), where 
the significant effects have entailed adolescent variables (Farley \& Kim-Spoon, 2016). Similarly, it has been argued that parental involvement training plays a determining role in the academic success of adolescents taking science and math courses (Rozek et al., 2015).

Family functioning during adolescence is relevant to understanding developmental trends, where mothers have received special attention for the specific contribution that they can offer. In this regard, it has been pointed out that mothers pay more attention to the academic performance of adolescents and there is a greater interaction with them in educational activities (Hsu et al., 2011), which have effects positive in academic results (Lansford et al., 2018), where a powerful predictor of adolescent academic achievement appears, such as mother's involvement. The foregoing is critical when considering that academic interest tends to decline during adolescence (Gnambs \& Hanfstingl, 2016) and the influence of mothers can be positively related to better trends (Lerner \& Grolnick, 2019). In this regard, it is also necessary to consider that academic performance of adolescents is affected by levels of autonomy in terms of cognitive (Gestsdottir et al., 2010), motivational (Froiland \& Oros, 2014; Ryan, 2016), and social dimensions (Kağitçibaşi \& Yalin, 2015), so that both the role of parents and adolescents must be included to understand the levels of academic achievement in adolescence.

The relation of parenting with adolescent adjustment considering autonomy of adolescents has been explored (Roche et al., 2019). In this context, studies with Latino population have reported positive outcomes for adolescent adjustment with orientedparenting to positive promotion of autonomy as opposed to coercive forms of socialization (Sher-Censor et al., 2011), although Latino parents could tend to express high levels of regulation and affection over adolescent's decision-making what shapes their behaviour trends (Halgunseth, 2019). However, differences in parenting outcomes may not be homogenous among Latino parents (Roche et al., 2014), which suggests that singularities are not necessarily due to ethnic origin but to other particularities of the relationship between parents and children.

In sum, parenting practices of mothers could affect academic the achievement of adolescents, but it is relevant to consider variables as adolescent autonomy in the analysis of this relation. Likewise, the specific relation of parenting practices and autonomy with academic achievement in adolescence has not been sufficiently explored with the Latino population.

In this context, this study is oriented to expand current knowledge about parenting practices and academic achievement in adolescence including the role of multidimensional autonomy. Regarding the above, as Figure 1 depicts, it is considered that parenting has a positive association with adolescents' academic achievement (H1), autonomy positively influences the academic performance of adolescents (H2), and adolescent autonomy mediates the relationship between parenting academic and achievement $(\mathrm{H} 3)$.

\section{Method}

\section{Participants}

The sample consisted of 229 mothers and their children from 10 schools of seven municipalities in Colombia, South America. The schools were intentionally selected for 


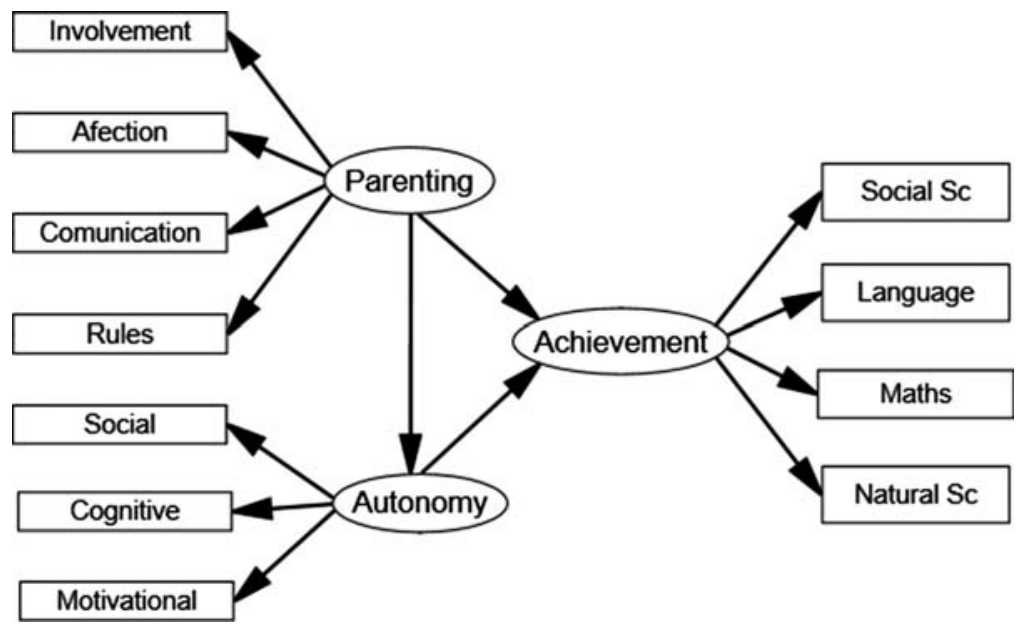

Figure 1. Theoretical model of relations between variables.

convenience considering ease of access. Among the inclusion criteria was that the adolescents were between 10 and 14 years old at the time of answering the questionnaires with no disability diagnoses. Adolescents covering students from public (65.9\%) and private schools according to the categorization of the Ministry of Education of Colombia (2018). The average age of mothers was 37.9 years $(\mathrm{SD}=6.9)$, and of children 11.8 years $(\mathrm{SD}=.93)$, including boys (49\%) and girls, that were in sixth $(58.1 \%)$ and seventh grades. Almost half of the mothers $(51,9 \%)$ had an educational diploma after school education, including mothers with a university degree (29.6\%), and only $23.6 \%$ did not have full school studies. $27.5 \%$ of mothers don't receive monthly incomes, $29.4 \%$ less than 233,84 USD, $2.6 \%$ between 233,84 USD and 475,89 USD, and $22.5 \%$ more than 475,89 USD. Most of the mothers were married at the moment of the study (92.4\%).

\section{Measures}

\section{Parenting practices}

The Parenting Practices and Academic Achievement Questionnaire (CRP-AAQ) (Aguirre-Dávila, 2017) measure actions of parents related to achievement of adolescents, and consists of 20 items (global $\alpha=0$.858) organized in four scales, which was confirmed by factor analysis (AFC) in the current study with an adequate fit to the proposed model of the items $(\mathrm{CMIN} / \mathrm{DF}=1.865$; CFI $=0.918$; RMSEA $=0.062$; SRMR $=0.066)$. Scales of CRP-AAQ evaluate: Parental Involvement ( 5 items, $\alpha=0.789$ ), which refers to strategies used by parents to be part of children's school life (e.g.: 'I help my child to study for tests'); Affective Manifestation (5 items, $\alpha=0.802$ ), is the way in which parents express emotions and teach their children to give and receive affection through caresses, words, hugs, and plays (e.g. 'If my child gets good grades, I congratulate and encourage $\mathrm{him} / \mathrm{her}$ to continue like this'); Communication (15 items, $\alpha=0.802$ ), it refers the way like parents communicate their expectations to their child in relation to the academic achievement, taking into account the attitude, the clarity of the message, and the time and place where they do it (e.g. 'I ask my child what she/he learned during the day.'); 
and Setting Rules ( 5 items, $\alpha=0.822$ ), is the way that parents give norms of behaviour to the child, making explicit their academic responsibilities and the consequences of compliance or non-compliance with this responsibilities (e.g. 'I punish my child when she/he gets a bad grade.'). Parents rated items with a four-point Likert scale ('Strongly Agree', 'Agree', 'Disagree', 'Strongly Disagree'). High scores indicated higher levels of positive parenting in each scale.

\section{Perceived academic autonomy}

The Academic Autonomy Perception Questionnaire (AAPQ) was originally proposed by Aguirre-Dávila and Ruiz (2016) to measure perception of autonomy in academic situations, and consists of 21 items $(\alpha=0.804)$ fitted in the present study in three scales according to a principal component analysis $(\mathrm{KMO}=0.780 p<.001)$ and a CFA $(\mathrm{CMIN} / \mathrm{DF}=1.666 ; \mathrm{RMSA}=0.054 ; \mathrm{SRMR}=0.066)$, as follows: cognitive autonomy $(\alpha=$ $0.605)$ refers to the processing of information, decision-making to coping everyday problems and the management of learning strategies (e.g. 'I reflect before acting.'); Social autonomy $(\alpha=0.635)$ refers to the way of interacting with people, including communication skills, conflict resolution and the ability to self-regulate emotions in social situations (e.g. 'I am intolerant with people who have different ideas than mine'); and Motivational autonomy ( $\alpha=0.641)$ is the desire to act for oneself (intrinsic motivation) and the desire to execute a behaviour to obtain an external reward (e.g. 'I am motivated to continually exceed my goals'). Adolescents rated items with a fourpoint Likert scale ('Never', 'Sometimes', 'Usually', 'Always'). High scores indicated higher levels of autonomy in each scale. Considering the number of items and the nature of the variables, reliability values greater than .6 are considered acceptable (George \& Mallery, 2016).

\section{Academic achievement}

Schools reported grades of students in Social Sciences, Language, Mathematics, and Natural Sciences, at the beginning and end of the second semester of the academic year. Average of grades was calculated and included for surveyed students. Grades are expressed in a one to five scale, where five represents the highest level.

\section{Procedure}

This study was approved for the Research System of Universidad Nacional de Colombia, and all ethical principles related to research with human participants were followed. A pilot study was developed with the research team to manualize the application requirements. In the first semester of the academic year, a letter was sent to directors of the schools selected to inform them about the objectives and procedures of the study and to invite them to participate in the research. After approval, specific materials and instructions were shared with schools to organize the details.

The instruments were administered at the beginning of the second semester of the academic year. The school staff distributed the CRP-AAQ to the mothers with a consent form. The mothers who agreed to participate returned the signed consent form and completed the questionnaire. A total of 229 surveys (46.4\% of distributed) were returned. Students whose mothers returned the questionnaire and the parent consent form received 
the AAPQ in a class during their regular school hours, where the questionnaire was completed under the supervision of teachers who supported research assistants in distributing the questionnaires to students. The instruments were administered at the beginning of the second quarter of the academic year. The school staff sent academic reports of the surveyed students. The raw data were submitted by the schools and digitized in the research group.

\section{Data analysis}

Data were cleaned and structured with the software SPSS version 24 (IBM, 2016a). Descriptive statistics and correlations of studied variables were calculated. Structural equations models (SEM) were run with the Amos software version 24 (IBM, 2016b). The fit of the model was tested considering small and non-significantly values of Chisquare $\left(\chi^{2}\right)$, normalized Chi-square $(\mathrm{CMIND} / \mathrm{DF})$ values under 3, Comparative Fit Index (CFI), Tucker-Lewis Index (TLI), and Goodness of Fit Index (GFI) values over 0.90, and Standardized Root Mean Squared Residual (SRMR) and Root Mean Square Error of Approximation (RMSEA) values under 0.080 (Hair et al., 2019; Kline, 2015). The comparison between models was made taking into account the values of the Akaike information criterion (AIC), preferring small values.

\section{Results}

As Table 1 indicates, parenting measures were significantly correlated with the exception of Rule-Setting that only correlated with Involvement. In this context, the relation between Communication and Expression of affection stood out when relating parenting practices $(r=0.552 ; p<.01)$. All autonomy measures were significantly correlated, and Cognitive and Motivational dimensions were the best related $(r=0.654 ; p<.01)$. In the academic achievement, Language and Mathematics had a relevant correlation $(r=0.512 ; p<.01)$, with all the academic subjects significantly correlated.

Communication was the only significantly correlated parenting variable with academic subjects, including Social Sciences $(r=0.141 ; p<.05)$ and Math $(r=0.137 ; p<.05)$. Social Sciences was the only academic achievement variable no significantly correlated with autonomy variables. Considering the above, there are sufficient reasons to consider the measured variables grouped in each latent variable and all the latent variables as independent.

The baseline SEM with original theoretical model (Figure 1) was tested, obtaining a poor adjustment in terms of: $\chi^{2}(41)=120.81$ with $p<.001, \mathrm{CMIN} / \mathrm{DF}=2.931$, $\mathrm{CFI}=0.876, \mathrm{TLI}=0.833$, GFI $=0.913$, RMSEA $=0.092$, and $\mathrm{SRMR}=0.072$. In this case, AIC value was equal to 170.181 . Considering the correlations and modification indices provided by the software used, an alternative model was tested to achieve better values, obtaining an AIC of 114.545 .

Since the Rule-Setting had no significant contribution to parenting in the original model, its exclusion allowed improvements in the fit of the obtained model. In this case, the global fit test resulted in a $\chi^{2}(31)=39.043$, with $\mathrm{p}$-value of .152 , which allows not to deny the hypothesis of equality of the covariance matrices of the model 


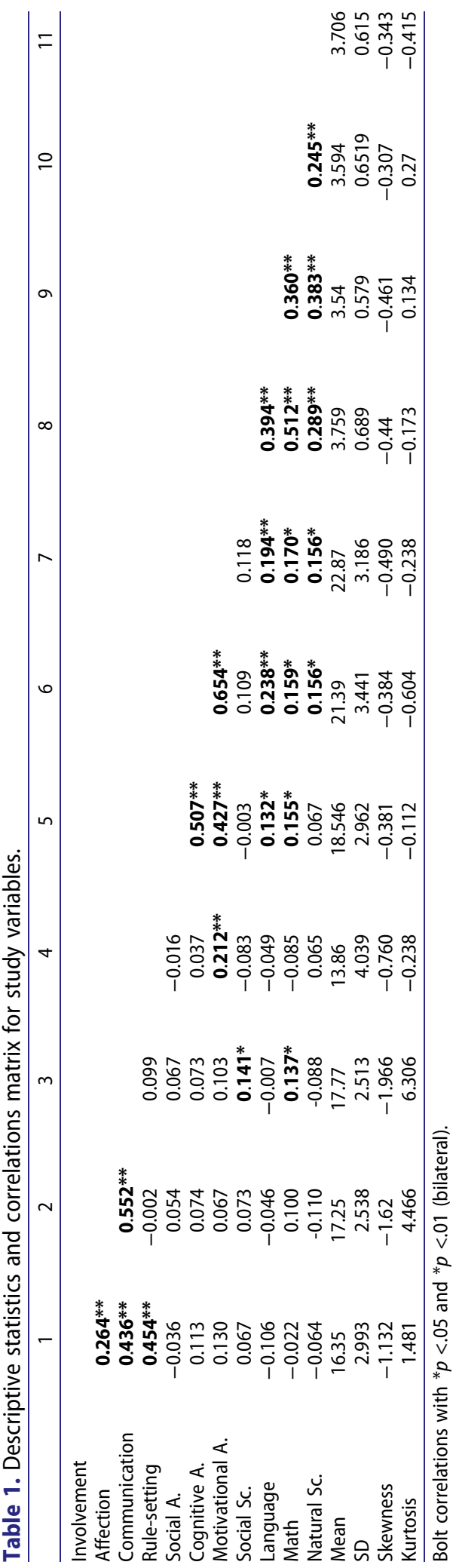




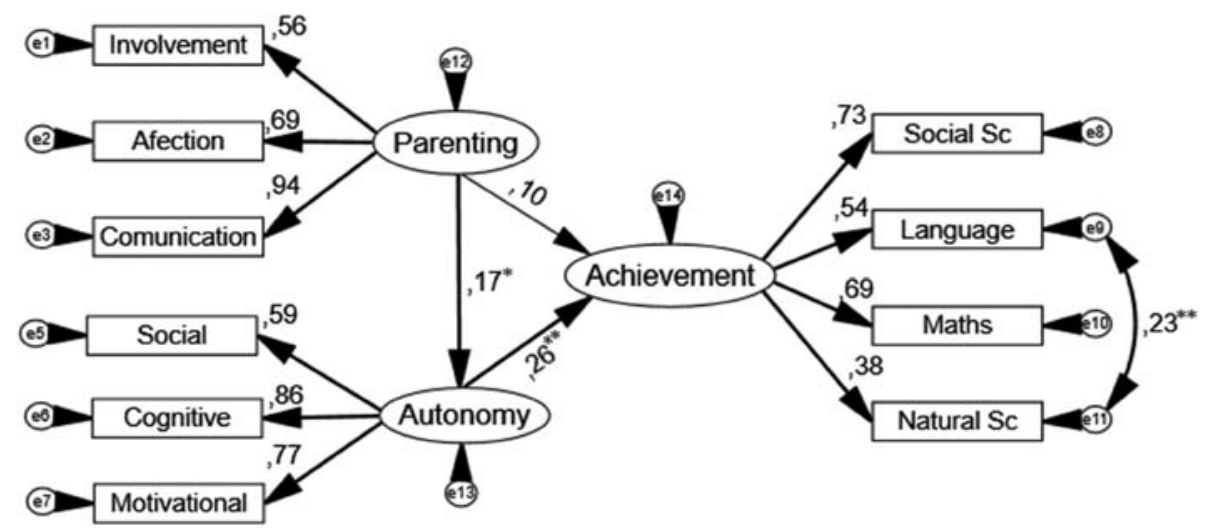

Figure 2. Structural model, with ${ }^{*} p<.05$ and ${ }^{* *} p<.01$.

and the observed data. Also, it was obtained a CMIN/DF of 1.259, a CFI of .986, a TLI of .980 , a GFI of .968 , a SRMR equals to .0515 and a RMSEA of .034, with a $90 \%$ confidence interval of [.000-.063]. AIC was equal to 87.043.

The estimated parameters don't show signs of misspecification and were stable throughout changes in the structure of the model. All fit indexes were considered in the range of satisfactory fit. Figure 2 displays the results of the structural modelling.

In the structural model exhibited in Figure 2, a direct relation of parenting with academic achievement ( $\mathrm{H} 1)$ was not significant in this model $(\beta=.10, \mathrm{p}=.232)$. It is confirmed the contribution of parenting to adolescent autonomy $(\mathrm{H} 2)(\beta=.17, \mathrm{p}=.025)$, and the effect of autonomy on academic achievement $(\mathrm{H} 3)(\beta=.26 ; \mathrm{p}<.01)$. Thus, the path that connects parenting with autonomy and the latter with achievement is significant.

Communication $(\lambda=.94, p<.001)$ and Expression of affection $(\lambda=.69, p<.001)$ were two relevant practices that contribute to parenting in the model, followed for Involvement $(\lambda=.56, p<.001)$. Cognitive $(\lambda=.86, p<.001)$ and Motivational Autonomy $(\lambda$ $=.77, p<.001)$ were the dimensions of greatest contribution when measuring autonomy, with a smaller but significant load of Social Autonomy $(\lambda=.59, p<.001)$. In the Academic Achievement side, Social Sciences had a relevant contribution in this part of the model $(\lambda=.73, p<.001)$, followed by Mathematics $(\lambda=.69, p<.001)$ and Language $(\lambda$ $=.54, p<.001)$, with a significative covariance between Language and Natural Sciences $(r=.23, p<.01)$.

\section{Discussion}

In this study, the direct path between mothers' parenting practices and academic performance was not significant, parenting had a direct effect on autonomy of the adolescents, and autonomy contributes to academic achievement mediating the relation between parenting and achievement, which suggests that parenting could have an indirect effect on adolescent achievement. Likewise, in each of the latent variables analyzed, some observable variables stood out by their load, as follows: communication in parenting and the cognitive dimension in autonomy. 
Although the relationship with parents is implied in the possibility of adolescents reaching educational goals (Parris et al., 2020), their direct contribution could report low values (Hsu et al., 2011). In the current study this relation has not been structurally supported, despite direct correlations between parent-child communication and some indicators of academic achievement. As previous works had indicated, parenting practices could affect outcomes in adolescence through the behavioral repertoire of adolescents (Soenens et al., 2019); thus, it is possible to pose that parenting affects adolescent outcomes considering autonomy trends (Roche et al., 2019), and this is supported when assessing academic achievement. In this way, parenting and autonomy configure a complex support system for the levels of performance in academic areas.

When parenting is measured in terms of involvement, expression of affection, and communication, their direct and positive effects are clear on the behavior of adolescents (Kocayörük et al., 2015; Wang \& Cai, 2017; Wuyts et al., 2018). The benefits of these practices are relevant in many domains of adolescence (Miranda et al., 2016; Morales-Castillo \& Aguirre-Davila, 2018), with a special place for communication, so that increases in the quality of this parenting practice favor the performance of adolescents (Trung \& Ducreux, 2013). This contrasts with a harsh setting of parental rules, because this may not contribute or negatively affect adolescent adjustment (Simpkins et al., 2009), which is supported by the exclusion of rule-setting in the final model.

As proposed by the Theory of Self-determination, relationships with parents provide a context for the emergence of multiple expressions of autonomy in adolescence (Ryan, 2016), providing explanations about the demands made on them, paying attention to feelings of their children, and, whenever possible, avoiding controlling their behaviors (Ryan et al., 2015). In the presented model, the autonomy of adolescents is mainly represented in terms of the cognitive and motivational dimensions, what supports previous approaches that postulates the integrated value of cognition and motivation in the contribution of autonomy to adolescent outcomes (Deci \& Ryan, 2017). The small but significant load of the social dimension shows the importance of the relational component in understanding autonomy, which provides support to the concept of a related autonomy (Kağitçibaşi, 2017).

In addition, sensitive academic areas of adolescent performance are implied in the proposed model. It has been found a covariation between language and science achievement, which could be supported by previous works where language skills benefit science works of adolescents (Uccelli et al., 2019), considering the common use of abilities such as writing in the scientific domain.

Adolescent performance in the academic domain represents a frequent cause of concern for educators and parents. Consequences of these conclusions impact the orientation of parental training, a decisive opportunity for social intervention with parents and adolescents (Morales-Castillo et al., 2019), where work with parents can be enriched with the complementarity of involvement, affection, and communication, while the adolescent participation can be focused on healthy development in terms of volitional, self-regulatory, and responsible decision-making. Specifically, school interventions could be enriched including positive parenting relation with adolescent development of cognitive and motivational autonomy, as a social source to strengthened academic performance in a critical period marked by decline (Gnambs \& Hanfstingl, 2016). In the same way, it could be relevant to consider that the mothers' perspective on the academic courses of their children affects the results obtained by adolescents (Harackiewicz et al., 2012). 
Among limitations, it is relevant to consider the characteristics of the sample, including the size, the age of adolescents and the origin of participants. About the rate of returned questionnaires, a possible reason of this amount of surveys could be related with a low parental participation in local schools, a common issue reported in Latino population (Ceballo et al., 2017). Finally, it is recommended to future studies a longitudinal design to confirm the long-term consequences of measured variables and evaluated relations. Likewise, non-considered variables could be included, like other components of parenting practices that affect adolescent behaviours and outcomes such as parental beliefs (Morales-Castillo, 2020) or children characteristics that affect behavioural trends in adolescence like gender (Vantieghem \& Van Houtte, 2018), which could help to deep in the nature of described relations.

\section{Disclosure statement}

No potential conflict of interest was reported by the author(s). All procedures performed in this study were in accordance with the ethical standards of the institutional research committee and international declarations related, or comparable ethical standards. Informed consent was included for all participants in this study.

\section{Funding}

This work was supported by Universidad Nacional de Colombia: [Grant Number 37519].

\section{Data availability statement}

The data set associated with the document is available in the database files of the Socialization and Parenting research group of the National University of Colombia.

\section{ORCID}

Eduardo Aguirre-Dávila (D) http://orcid.org/0000-0003-3292-5414

Miguel Morales-Castillo (D) http://orcid.org/0000-0001-6626-6694

Manuel Moreno-Vásquez (i) http://orcid.org/0000-0002-9813-6912

\section{References}

Aguirre-Dávila, E. (2015). Prácticas de crianza, temperamento y comportamiento prosocial de estudiantes de educación básica. Revista Latinoamericana de Ciencias Sociales, Niñez y Juventud, 13(1), 223-243. https://doi.org/10.11600/1692715x.13113100314

Aguirre-Dávila, E. (2017). Parenting practices and academic achievement questionnaire/ Cuestionario de Prácticas de Crianza y Logro Académico. Grupo de Investigación en Socialización y Crianza, Universidad Nacional de Colombia.

Aguirre-Dávila, E., \& Ruiz, S. (2016). Academic autonomy perception questionnaire/Cuestionario de Percepción de la Autonomía Académica. Grupo de Investigación en Socialización y Crianza, Universidad Nacional de Colombia.

Campione-Barr, N. (2020). Development of autonomy. In S. Hupp \& J. D. Jewell (Eds.), The encyclopedia of child and adolescent development (pp. 1-9). John Wiley \& Sons. https://doi.org/10. 1002/9781119171492.wecad468 
Campione-Barr, N., \& Smetana, J. G. (2018). Families with adolescents. In B. H. Fiese (Ed.), APA handbook of contemporary family psychology: Foundations, methods, and changing forms (Vol. 1, pp. 593-609). American Psychological Association.

Ceballo, R., Jocson, R. M., \& Alers-Rojas, F. (2017). Parental educational involvement and Latino children's academic attainment. In N. Cabrera, \& B. Leyendecker (Eds.), Handbook on positive development of Minority children and Youth (pp. 343-359). Springer. https://doi.org/10.1007/ 978-3-319-43645-6_21

Degol, J., Wang, M., Ye, F., \& Zhang, C. (2017). Who makes the cut? Parental involvement and math trajectories predicting college enrollment. Journal of Applied Developmental Psychology, 50, 60-70. https://doi.org/10.1016/j.appdev.2017.03.007

de Looze, M., van den Eijnden, R., Verdurmen, J., Vermeulen-Smit, E., Schulten, I., Vollebergh, W., \& ter Bogt, T. (2012). Parenting practices and adolescent risk behavior: Rules on smoking and drinking also predict cannabis use and early sexual debut. Prevention Science, 13, 594-604. https://doi.org/10.1007/s11121-012-0286-1

Deci, E., \& Ryan, R. (2017). Parenting and the facilitation of autonomy and well-being in development. In R. M. Ryan \& E. L. Deci (Eds.), Self-determination theory: Basic psychological needs in motivation, development and wellness (pp. 319-350). Guilford Press.

Farley, J. P., \& Kim-Spoon, J. (2016). Parenting and adolescent self-regulation mediate between family socioeconomic status and adolescent adjustment. The Journal of Early Adolescence, 37 (4), 502-524. https://doi.org/10.1177/0272431615611253

Froiland, J., \& Oros, E. (2014). Intrinsic motivation, perceived competence and classroom engagement as longitudinal predictors of adolescent reading achievement. Educational Psychology, 34 (2), 119-132. https://doi.org/10.1080/01443410.2013.822964

George, D., \& Mallery, P. (2016). Descriptive statistics. In D. George \& P. Mallery (Eds.), IBM SPSS statistics 23 step by step a simple guide and reference (pp. 112-120). Routledge. https://doi.org/ 10.4324/9781315545899

Gestsdottir, S., Bowers, E., Eye, A., Napolitano, C. M., \& Lerner, R. M. (2010). Intentional self regulation in middle adolescence: The emerging role of loss-based selection in positive youth development. Journal of Youth and Adolescence, 39, 764-782. https://doi.org/10.1007/s10964-0109537-2

Gnambs, T., \& Hanfstingl, B. (2016). The decline of academic motivation during adolescence: An accelerated longitudinal cohort analysis on the effect of psychological need satisfaction. Educational Psychology, 36(9), 1691-1705. https://doi.org/10.1080/01443410.2015.1113236

Grolnick, W. S., Levitt, M., \& Caruso, A. (2017). Adolescent autonomy in context. Facilitative parenting in different cultures, domains, and settings. In B. Soenens, M. Vansteenkiste, \& S. Van Petegem (Eds.), Autonomy in adolescent development, towards conceptual clarity (pp. 94118). Routledge. https://doi.org/10.4324/9781315636511-5

Grolnick, W. S., Raftery-Helmer, J. N., Flamm, E. S., Marbell, K. N., \& Cardemil, E. V. (2015). Parental provision of academic structure and the transition to middle school. Journal of Research on Adolescence, 25, 668-684. https://doi.org/10.1111/jora.12161

Hair, J.F., Black, W.C., Babin, B., \& Anderson, R.E. (2019). Multivariate data analysis. Cengage.

Halgunseth, L. (2019). Latino and Latin American parenting. In M. H. Bornstein (Ed.), Handbook of parenting (Vol. 4: Social Conditions and Applied Parenting, pp. 24-56). Routledge. https:// doi.org/10.4324/9780429398995-2

Hanewald, R. (2013). Transition between primary and secondary school: Why it is important and how it can be supported. Australian Journal of Teacher Education, 38(1), 62-74. https://doi.org/ 10.14221/ajte.2013v38n1.7

Harackiewicz, J. M., Rozek, C. S., Hulleman, C. S., \& Hyde, J. S. (2012). Helping parents to motivate adolescents in mathematics and science: An experimental test of a utility-value intervention. Psychological Science, 23, 899-906. https://doi.org/10.1177/0956797611435530

Hollmann, J., Gorges, J., \& Wild, E. (2016). Motivational antecedents and consequences of the mother-adolescent communication. Journal of Child and Family Studies, 25, 767-780. https://doi.org/10.1007/s10826-015-0258-8 
Hsu, H.-Y., Zhang, D., Kwok, O.-M., Li, Y., \& Ju, S. (2011). Distinguishing the influences of father's and mother's involvement on adolescent academic achievement: Analyses of Taiwan Education Panel Survey data. The Journal of Early Adolescence, 31(5), 694-713. https://doi. org/10.1177/0272431610373101

IBM. (2016a). Statistical Package for the Social Sciences (SPSS), version 24.

IBM. (2016b). Analysis of Moment Structures (AMOS), version 24.

Kağitçibaşi, Ç. (2017). Parenting and the development of the autonomous-related self. In Ç. Kağitçibaşi (Ed.), Family, self, and human development across cultures, theory and applications (pp. 165-203). Routledge. https://doi.org/10.4324/9781315205281

Kağitçibaşi, Ç., \& Yalin, C. (2015). Family in adolescence: Relatedness and autonomy across cultures. In L. A. Jensen (Ed.), Oxford library of psychology. The Oxford handbook of human development and culture: An interdisciplinary perspective (pp. 410-424). Oxford University Press. https://doi.org/10.1093/oxfordhb/9780199948550.013.25

Kirshner, B. (2018). Activism. In R. Levesque (Ed.), Encyclopedia of adolescence (2nd ed., pp. 6976). Springer International Publishing.

Kline, R. (2015). Principles and practice of structural equation modeling. Guilford Press.

Kocayörük, E., Altıntas, E., \& İçbay, M. A. (2015). The perceived parental support, autonomousself and well-being of adolescents: A cluster-analysis approach. Journal of Child and Family Studies, 24(6), 1819-1828. https://doi.org/10.1007/s10826-014-9985-5

Lansford, J. E., Godwin, J., Al-Hassan, S. M., Bacchini, D., Bornstein, M. H., Chang, L., Chen, B.-B., Deater-Deckard, K., Di Giunta, L., Dodge, K. A., Malone, P. S., Oburu, P., Pastorelli, C., Skinner, A. T., Sorbring, E., Steinberg, L., Tapanya, S., Alampay, L. P., Uribe Tirado, L. M., Zelli, A. (2018). Longitudinal associations between parenting and youth adjustment in twelve cultural groups: Cultural normativeness of parenting as a moderator. Developmental Psychology, 54 (2), 362-377. https://doi.org/10.1037/dev0000416

Lerner, R., \& Grolnick, W. (2019). Maternal involvement and children's academic motivation and achievement: The roles of maternal autonomy support and children's affect. Motivation and Emotion, 44(3), 373-388. https://doi.org/10.1007/s11031-019-09813-6

Marion, D., Laursen, B., Kiuru, N., Nurmi, J., \& Salmela-Aro, K. (2014). Maternal affection moderates friend influence on schoolwork engagement. Developmental Psychology, 5, 766-771. https://doi.org/10.1037/a0034295

Ministry of Education of Colombia. (2018). Database of registered schools in Colombia. Electronic communication.

Miranda, M. C., Affuso, G., Esposito, C., \& Bacchini, D. (2016). Parental acceptance-rejection and adolescent maladjustment: Mothers' and fathers' combined roles. Journal of Child and Family Studies, 25, 1352-1362. https://doi.org/10.1007/s10826-015-0305-5

Morales-Castillo, M. (2020). Las creencias parentales en el proceso de crianza y sus relaciones con el comportamiento adolescente. Psicologia USP (in edition).

Morales-Castillo, M., \& Aguirre-Davila, E. (2018). Involucramiento parental basado en el hogar y logro académico en la adolescencia. Revista Colombiana de Psicología, 27, 137-160. https://doi. org/10.15446/rcp.v27n2.66212

Morales-Castillo, M., Aguirre-Davila, E., \& Durán-Urrea, L. (2019). Los contenidos de la formación parental y sus implicaciones para el comportamiento de los adolescentes: Elementos desde una revisión. Saúde e Sociedade, 28(3), 224-238. https://doi.org/10.1590/ s0104-12902019181111

Morgan, P. L., Farkas, G., Hillemeier, M. M., \& Maczuga, S. (2016). Science achievement gaps begin very early, persist, and are largely explained by modifiable factors. Educational Researcher, 45(1), 18-35. https://doi.org/10.3102/0013189X16633182

Parris, L., Banks, B. M., Christie, M., Lucas-Nihei, J. N., Lacey, H., \& Swerdlik, M. E. (2020). School context. In S. Hupp \& J. D. Jewell (Eds.), The encyclopedia of child and adolescent development (pp. 1-15). John Wiley \& Sons. https://doi.org/10.1002/9781119171492.wecad419

Power, T. G., Sleddens, E. F. C., Berge, J., Connell, L., Govig, B., Hennessy, E., Liggett, L., Mallan, K., Santa Maria, D., Odoms-Young, A., \& St. George, S. M. (2013). Contemporary research on 
parenting: Conceptual, methodological, and translational issues. Childhood Obesity, 9(s1), S-87S-94. https://doi.org/10.1089/chi.2013.0038

Ren, F., Li, Y., \& Zhang, J. (2017). Perceived parental control and Chinese middle school adolescents' creativity: The mediating role of autonomous motivation. Psychology of Aesthetics, Creativity, and the Arts, 11(1), 34-42. https://doi.org/10.1037/aca0000078

Roche, K., Lambert, S., White, R., Calzada, E., Little, T., Kuperminc, G., \& Schulenberg, J. (2019). Autonomy-related parenting processes and adolescent adjustment in Latinx immigrant families. Journal of Youth and Adolescence, 48, 1161-1174. https://doi.org/10.1007/s10964019-01010-5

Roche, K. M., Caughy, M. O., Schuster, M. A., Bogart, L. M., Dittus, P. J., \& Franzini, L. (2014). Cultural orientations, parental beliefs and practices, and Latino adolescents' autonomy and independence. Journal of Youth and Adolescence, 43(8), 1389-1403. https://doi.org/10.1007/ s10964-013-9977-6

Rodríguez-Fernández, A., Antonio-Agirre, I., Ramos-Díaz, E., \& Revuelta-Revuelta, L. (2019). The role of affect-communication and rule setting in perceived family support and school adjustment. European Journal of Education and Psychology, 13(1), 5-18. https://doi.org/10.30552/ ejep.v13i1.288

Rozek, C. S., Hyde, J. S., Svoboda, R. C., Hulleman, C. S., \& Harackiewicz, J. M. (2015). Gender differences in the effects of a utility-value intervention to help parents motivate adolescents in mathematics and science. Journal of Educational Psychology, 107(1), 195-206. https://doi. org/10.1037/a0036981

Ryan, R. M. (2016). The empirical study of human autonomy using self-determination theory. In R. Sternberg, S. Fiske, \& D. Foss (Eds.), Scientists making a difference: One hundred eminent behavioral and brain scientists talk about their most important contributions (pp. 311-315). Cambridge University Press. https://doi.org/10.1017/CBO9781316422250.068

Ryan, R. M., Deci, E. L., Grolnick, W. S., \& La Guardia, J. G. (2015). The significance of autonomy and autonomy support in psychological development and psychopathology. In D. Cicchetti \& D. J. Cohen (Eds.), Developmental psychopathology: Theory and method (pp. 795-849). Wiley. https://doi.org/10.1002/9780470939383.ch20

Sher-Censor, E., Parke, R. D., \& Coltrane, S. (2011). Parents' promotion of psychological autonomy, psychological control, and Mexican-American adolescents' adjustment. Journal of Youth and Adolescence, 40(5), 620-632. https://doi.org/10.1007/s10964-010-9552-3

Simpkins, S. D., Bouffard, S. M., Dearing, E., Kreider, H., Wimer, C., Caronongan, P., \& Weiss, H. B. (2009). Adolescent adjustment and patterns of parents' behaviors in early and middle adolescence. Journal of Research on Adolescence, 19, 530-557. https://doi.org/10.1111/j.15327795.2009.00606.x

Smetana, J. G. (2017). Current research on parenting styles, opinions, and beliefs. Current Opinions in Psychology, 15, 19-25. https://doi.org/10.1016/j.copsyc.2017.02.012

Smetana, S., Robinson, J., \& Rote, W. (2015). Socialization in adolescence. In J. E. Grusec \& P. D. Hastings (Eds.), Handbook of socialization (pp. 60-84). Guilford Press.

Soenens, B., Vansteenkiste, M., \& Beyers, W. (2019). Parenting adolescents. In M. H. Bornstein (Ed.), Handbook of parenting (Vol. 1: Children and Parenting, pp. 111-117). Routledge. https://doi.org/10.4324/9780429440847-4

Soenens, B., Vansteenkiste, M., Van Petegem, S., Beyers, W., \& Ryan, R., (2017). How to solve the conundrum of adolescent autonomy? On the importance of distinguishing between independence and volitional functioning. In B. Soenens, M. Vansteenkiste, \& S. Van Petegem (Eds.), Autonomy in adolescent development, towards conceptual clarity (pp. 1-32). Routledge. https://doi.org/10.4324/9781315636511-1

Song, J., Bong, M., Lee, K., \& Kim, S. (2015). Longitudinal investigation into the role of perceived social support in adolescents' academic motivation and achievement. Journal of Educational Psychology, 107(3), 821-841. https://doi.org/10.1037/edu0000016

Suizzo, M. (2020). Parent-child relationships. In S. Hupp \& J. D. Jewell (Eds.), The encyclopedia of child and adolescent development (pp. 1-13). John Wiley \& Sons. https://doi.org/10.1002/ 9781119171492.wecad408 
Trung, B., \& Ducreux, E. (2013). Parental influence and academic achievement among middle school students: Parent perspective. Journal of Human Behavior in the Social Environment, 23, 579-590. https://doi.org/10.1080/10911359.2013.765823

Uccelli, P., Deng, Z., Phillips Galloway, E., \& Qin, W. (2019). The role of language skills in midadolescents' science summaries. Journal of Literacy Research, 51(3), 357-380. https://doi.org/10. 1177/1086296X19860206

Vantieghem, W., \& Van Houtte, M. (2018). Differences in study motivation within and between genders: An examination by gender typicality among early adolescents. Youth \& Society, 50(3), 377-404. https://doi.org/10.1177/0044118X15602268

Wang, H., \& Cai, T. (2017). Parental involvement, adolescents' self-determined learning and academic achievement in Urban China. International Journal of Psychology, 52(1), 58-66. https:// doi.org/10.1002/ijop.12188

Wang, M. T., Hill, N. E., \& Hofkens, T. (2014). Parental involvement and African American and European American adolescents' academic, behavioral, and emotional development in secondary school. Child Development, 85, 2151-2168. https://doi.org/10.1111/cdev.12284

Wuyts, D., Soenens, B., Vansteenkiste, M., \& Van Petegem, S. (2018). The role of observed autonomy support, reciprocity, and need satisfaction in adolescent disclosure about friends. Journal of Adolescence, 65, 141-154. https://doi.org/10.1016/j.adolescence.2018.03.012 